A. Wolujewicz ${ }^{1}$, M. Lawton ${ }^{1}$, M. Wood ${ }^{1}$, N. Theobald ${ }^{2}$

${ }^{1}$ Liverpool Centre for Sexual Health ${ }^{2}$ Nick Theobald Consulting

Twitter is a free, online social networking service through which users can read and send instant messages called Tweets with a maximum limit of I 40 characters

Twitter connects with a mixed, international audience

Twitter can keep us informed of key published research, relevant headline news, public health issues and guideline updates

Recent Twitter themes discussed include PrEP and gonorrhoea resistance

Twitter is also used for sharing practical information such as conference deadlines

In December 2015, BASHH escalated its Twitter strategy for increased presence on social media

\section{Y @BASHH_UK}

\section{BASHH has 3814 Twitter followers: $63 \%$ female $81 \%$ in UK $5 \%$ in United States $1 \%$ in Spain $1 \%$ in Northern Ireland}

Twitter Analytics data below shows the current impact of BASHH on Twitter and includes:

Tweet Impressions = no. of times each Tweet is seen

Profile Visits = visits to BASHH's Twitter profile

Mentions by other Twitter users

Number of new Twitter followers

Twitter Analytics data for each month from October 20 I5:

\begin{tabular}{|c|c|c|c|c|c|}
\hline & Tweets & Tweet Impressions & Profile Visits & Mentions & New followers \\
\hline October 2015 & 10 & 6559 & 810 & 139 & 92 \\
\hline November 2015 & 18 & 19200 & 1122 & 105 & 120 \\
\hline December 2015 & 31 & 36600 & 1548 & 83 & 67 \\
\hline January 2016 & 49 & 45500 & 2398 & 222 & 120 \\
\hline February 2016 & 33 & 28100 & 2394 & 125 & 108 \\
\hline March 2016 & 28 & 31300 & 2012 & 129 & 94 \\
\hline April 2016 & 14 & 30000 & 1555 & 161 & 112 \\
\hline May 2016 & 11 & 33800 & 1333 & 113 & 106 \\
\hline June 2016 & 20 & 26200 & 1487 & 89 & 103 \\
\hline
\end{tabular}

\section{How do I use Twitter?}

- Go to Twitter.com or download the free app to your mobile device

- Create an account and 'handle' (@xxxxxx)

- Choose who to follow

- Start Tweeting

\section{Summary}

BASHH's Twitter activity is reaching a large audience and increasing. All individuals working in sexual health and HIV should consider using Twitter to support wider engagement with their professional network. Search \# BASHH2016 during the conference for updates. 